\title{
Crystalline structure and properties of diamond-like materials
}

\author{
E. A. Belenkov ${ }^{1}$, M. M. Brzhezinskaya ${ }^{2}$, V. A. Greshnyakov ${ }^{1}$ \\ ${ }^{1}$ Chelyabinsk State University, Bratiev Kashirinykh, 129, Chelyabinsk, 454001, Russia \\ ${ }^{2}$ Helmholtz-Zentrum Berlin für Materialien und Energie, \\ Albert-Einstein-Strasse, 15, Berlin, 12489, Germany \\ belenkov@csu.ru, maria.brzhezinskaya@helmholtz-berlin.de, greshnyakov@csu.ru
}

PACS 61.50.Ah, 81.05.ug

DOI 10.17586/2220-8054-2017-8-1-127-136

\begin{abstract}
Using density functional theory, the structures and properties of carbon diamond-like phases, all of whose atoms occupy equivalent crystallographic positions, were studied. Structures of these phases were obtained by linking or superposing ofcarbon clusters. It was found that thirteen such phases can exist. The calculated structural characteristics and properties (density, cohesive energy, bandgap, bulk modulus, hardness, and $\mathrm{x}$-ray diffraction pattern) of the diamond-like phases under study differ significantly from respective parameters of cubic diamond.
\end{abstract}

Keywords: Diamond crystal, diamond-like carbon, fullerenes, modeling.

Received: 18 September 2016

Revised: 21 November 2016

\section{Introduction}

Fullerene is a nano-allotropic carbon form consisting of 3-coordinated atoms [1-3] whose structure complies with the Euler's rule for convex polyhedrons. The fullerene surface is formed by carbon atoms located in the pentagon and hexagon vertices. Fullerenes can be practically used in medicine and nanophotonics, as well as in producing adsorbers, abrasive agents and construction materials $[4,5]$. Highly strong construction materials may be obtained by bulk compression of fullerene condensates (fullerites). Pioneering work in this field was performed by several research groups [6-9]. When pressure is about $1 \mathrm{GPa}$ and temperature is $200^{\circ} \mathrm{C}$, some atoms of fullerite initially consisting only of tri-coordinated carbon atoms begin transforming to the tetra-coordinated state [10]. This gives rise to inter-fullerene covalent bonds and initiates formation of a hybrid structure consisting of tri- and tetracoordinated atoms. The increase in pressure results in an increase in the fraction of tetra-coordinated atoms; thus, when pressure exceeds $17 \mathrm{GPa}$, almost all the atoms transfer to the tetra-coordinated state, and phases of diamondlike structures arise $[9,11-13]$. Theoretical study of diamond-like phases that can be obtained from fullerenes and carbon clusters was performed in a number of works [14-18]. Theoretical analyses have shown the possibility of existence of six phases of this type: supercubane and tetrahedral diamond [14], "simple cubic fullerite" $C_{24}$ [15], T-carbon [16], carbon sodalite [17], and face-centered cubic $\mathrm{C}_{12}$ phase $\left(\mathrm{fcc}-\mathrm{C}_{12}\right)$ [18]. Additional investigations should be performed to ascertain if other diamond-like phases can be obtained from carbon clusters. A schematic diagram for deriving diamond-like phases from various precursors was proposed in [19]. Earlier, this scheme was used to study diamond-like phases of the L-, T- and S-groups obtained from graphene layers, carbon nanotubes, and three dimensionally (3D) covalently bonded graphites, respectively [20,21]. This paper presents calculations for the structures and properties of thirteen carbon diamond-like phases with crystallographically equivalent atomic positions simulated by either linking or superposing the last precursor group, namely, carbon clusters.

\section{Calculation methods}

The diamond-like carbon phases were obtained from carbon clusters consisting of tri-coordinated atoms via the technique described in [19]. Diamond-like phases arising from cluster nanoprecursors of the $\left[0 \mathrm{D}_{c}, 3\right]$ structural group are referred to as $\mathrm{C}$-phases.

Since in this work we studied diamond-like phases with crystallographically equivalent atom positions, clusters with equivalent atom positions were considered as possible precursors for their formation. Such clusters are carbon molecules with carbon skeletons shaped as regular and semi-regular polyhedrons and prisms [19]. The number of regular and semi-regular clusters is limited to three and seven, respectively, while the number of prismatic clusters is infinite. Further decrease in the number of clusters is because any three dimensionally ordered structure of the diamond-like phase can have only 2-, 3-, 4- and 6-fold symmetry axes. Due to this restriction, the following clusters cannot be used as precursors: all $5 \overline{3} \mathrm{~m}$ semiregular clusters $\left(\mathrm{C}_{20}\right.$, two polymorphs of $\mathrm{C}_{60}$, and $\left.\mathrm{C}_{120}\right)$ and prismatic clusters except for $\mathrm{C}_{6}, \mathrm{C}_{12}, \mathrm{C}_{16}$, and $\mathrm{C}_{24}$. In the two last prismatic clusters $\left(\mathrm{C}_{16}\right.$ and $\left.\mathrm{C}_{24}\right)$, 8- and 
12-fold symmetry axes (respectively) may degenerate into the 4- and 6-fold axes in case of changes in lengths of a half of the prism base bonds. Fig. 1 presents carbon clusters used to construct diamond-like phases.

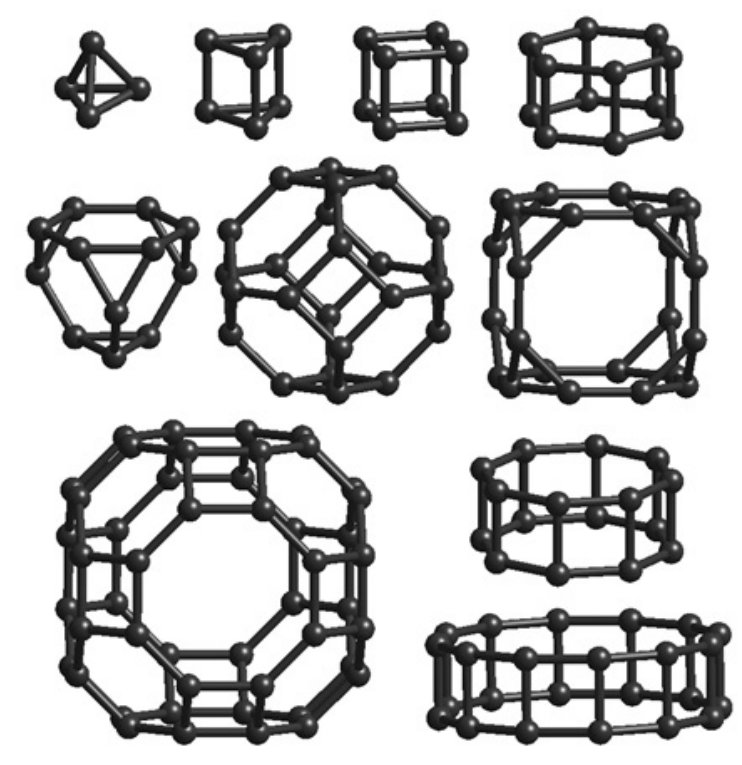

FIG. 1. Fullerene-like clusters

The primary mechanism for modeling C-phase structures is cluster linking that leads to formation of bonds between pairs or groups of atoms of neighboring clusters. Phases formed as a result of cluster linking are referred to as CA-phases [22]. The other method for obtaining diamond-like C-phases consists of superposing equivalent faces of neighboring clusters with subsequent removal of a half of combined atoms. The neighboring clusters may be combined by either vertices, or edges, or faces. In cases where the edges or vertices are combined, the atom coordination number will be five or six, respectively. The atom coordination number in diamond-like phases should be four; this number occurs only when cluster faces are combined. To designate C-phases obtained by superposing carbon clusters, symbols "CB" are used.

To create 3D crystalline structures of diamond-like phases, each cluster should be linked or superposed with minimum three nearest clusters so as to form a structural motif similar to uninodal $3 \mathrm{D}$ lattices of the $\left[3 \mathrm{D}_{c}, 3\right]$ structural group [19]. The cluster coordination number corresponding to close packing may be a maximum of twelve. However, not every type of 3D cluster packing can be used to form C-phases with equivalent atom positions. The possibility of constructing diamond-like phases is restricted by the number and shape of carbon cluster faces. Table 1 presents the results of analyzing all possible coordination numbers of clusters from which diamond-like phases may be derived.

Geometrical optimization of diamond-like phase crystalline structures was performed by using the density functional theory (DFT) method [23] realized in program code Quantum Espresso [24]. Energetic characteristics and densities of the C-phase electronic states were calculated in the Generalized Gradient Approximation (GGA) and Local Density Approximation (LDA) using the B3LYP [25] and Perdew-Zunger [26] exchange-correlation energy functionals respectively. The ion core effect was accounted for via the norm-conserving pseudopotentials. Calculation was performed by using Brillouin-zone k-point grids $12 \times 12 \times 12$ calculated by the Monkhorst-Pack method [27]; the cut-off energy was 60 Rydberg.

Bulk moduli of the diamond-like phases were determined by the method presented in [28]. Atomic volumes and total energies necessary for calculating the bulk moduli were evaluated by the DFT-GGA method at the relative phase volume variation of up to $3.5 \%$. The phase hardness was calculated by the Li's method [29]. C-phase powder x-ray diffraction (XRD) patterns were simulated via the standard technique described in [30] assuming that $\lambda_{\mathrm{Cu}-\alpha}=1.5405 \AA$ and using the unit cell parameters and atom coordinates calculated by the DFT-LDA method.

\section{Results and Discussion}

Theoretical analysis performed in the scope of this work showed the possibility of creating fifteen different diamond-like structures from carbon clusters with equivalent atom positions. Fourteen of these structures can be formed by cluster linking, while the remaining structure can be created by cluster superposition. Geometric 
TABLE 1. Structural characteristics and coordinations of fullerene-like clusters necessary for obtaining the diamond-like phases

\begin{tabular}{|c|c|c|c|c|}
\hline \multirow{2}{*}{ Cluster } & \multirow{2}{*}{ Ring parameter } & \multirow{2}{*}{ Point group } & \multicolumn{2}{|c|}{ Coordination number } \\
\cline { 4 - 5 } & & & Linking & Superposition \\
\hline $\mathrm{C}_{4}$ & $3^{3}$ & $\overline{4} 3 m$ & 4 & - \\
\hline $\mathrm{C}_{6}$ & $3^{1} 4^{2}$ & $\overline{6} m 2$ & 3,6 & - \\
\hline $\mathrm{C}_{8}$ & $4^{3}$ & $m \overline{3} m$ & 4,8 & - \\
\hline $\mathrm{C}_{12}$ & $4^{2} 6^{1}$ & $6 / m m m$ & $3,6,12$ & 3 \\
\hline $\mathrm{C}_{12}$ & $3^{1} 6^{2}$ & $\overline{4} 3 m$ & $4,6,12$ & 4 \\
\hline $\mathrm{C}_{16}$ & $4^{2} 8^{1}$ & $8 / m m m$ & 4 & 4 \\
\hline $\mathrm{C}_{24}$ & $4^{1} 6^{2}$ & $m \overline{3} m$ & $4,6,8,12$ & 4,6 \\
\hline $\mathrm{C}_{24}$ & $3^{1} 8^{2}$ & $m \overline{3} m$ & $3,6,8,12$ & 3,8 \\
\hline $\mathrm{C}_{24}$ & $4^{2} 12^{1}$ & $12 / m m m$ & 6,12 & 6 \\
\hline $\mathrm{C}_{48}$ & $4^{1} 6^{1} 8^{1}$ & $m \overline{3} m$ & $6,8,12$ & $6,8,12$ \\
\hline
\end{tabular}

optimization of those structures by the DFT method proved the possible stable existence of thirteen diamond-like C-phases whose structures are shown in Fig. 2. Twelve CA-phases (Fig. 2(a-1)) were obtained by linking together carbon clusters depicted in Fig. 1. Clusters corresponding to each phase are presented in Table 2. Only one phase, i.e., CB, was formed by cluster superposition (Table 2). The symmetry of the final phases' crystal lattices did not change in the course of geometrical optimization of initial structures obtained from linked clusters. In the diamond-like phases, the shape of cluster-like structural units remained similar to that of initial clusters. Two C-phases appeared to be unstable: a highly symmetrical (I432) structure formed by linked $\mathrm{C}_{24}$ clusters in the bcc packing and a chiral $\left(\mathrm{P}_{2} 22\right)$ structure consisting of polymerized tetrahedral $\mathrm{C}_{4}$ clusters located in the phase SA2 lattice sites [26]. In the process of DFT optimization, lattice destruction of these phases was observed.

For thirteen C-phases, ring parameters (Wells' parameters), space groups of symmetry, unit cell parameters (a, $\mathrm{c}$, and Z), and deformation parameters (Def and Str) were determined (Table 2). Analyzing the ring parameters of the diamond-like phases, we have found out that C-phase structures inevitably inherit three covalent bond rings that are characteristic of the clusters-precursors (see also Table 1). Three-membered rings were observed in four phases, four-membered rings - in eleven phases, 6-membered rings - in eight phases, 8-membered rings - in nine phases, and twelve-membered rings were observed in the structures of two C-phases. The C-phase unit cells belong to the following syngonies: cubic (CA1, CA3, CA4, CA6-CA9, CA12, CB), hexagonal (CA2, CA11), tetragonal (CA5), and trigonal (CA10) (see Table 2). Calculated unit-cell parameters agree rather well with the experimental parameters for cubic diamond [2], hexagonal diamond (lonsdaleite) [31], $\mathrm{C}_{8}$ [32], and simple cubic diamond polymorph [33].

Crystalline structure distortion of the diamond-like phases relative to the cubic diamond structure (LA1) is characterized by parameters Def [20] and Str [21]. The C-phase deformation parameter Def accounting for the deviation of the interatomic bond angles of a certain structure from the diamond angle of $109.47^{\circ}$ varies from 81.1 (CA6) to $254^{\circ}$ (CA1) (Table 2). The C-phase stress parameter Str characterizing deviations of interatomic bond lengths from the diamond bond length ranges from 0.02 (CA6) to $0.25 \AA$ (CA1) for the DFT-GGA method and from 0.01 (CA6) to $0.23 \AA$ (CA1) for the DFT-LDA method (Table 2).

The diamond-like phase densities were determined by using calculated equilibrium parameters of unit cells at zero pressure (Table 3). All the C-phase densities were shown to be lower than the diamond one from 18 to $65 \%$ for the CA6 and CA12 phases, respectively.

In addition, cohesive energies $\left(\mathrm{E}_{c o h}\right)$ were determined for the $\mathrm{C}$-phases (their values are listed in Table 3 ). The cubic diamond (LA1) cohesive energies calculated by the GGA and LDA methods proved to exceed experimental values [34] by 0.49 and $1.59 \mathrm{eV} /$ atom, respectively. Cohesive energies of the diamond-like C-phases proved to be lower than that of diamond by a value ranging from 5.3 (CA6) to $19.2 \%$ (CA12). Phases CA3, CA6, and $\mathrm{CB}$ are the most stable among all the $\mathrm{C}$-phases since their cohesive energies are maximal. A correlation between the deformation parameters and the cohesive energy is observed: $\mathrm{E}_{c o h}$ decreases linearly with increasing a combination of Str and Def (Fig. 3). The dependence presented in Fig. 3 is common for the diamond-like C-phases and diamond-like phases of the L-, T- and S-types previously studied [20-22]. As another evidence of stability of not-yet synthesized carbon C-phases, one can consider the fact that they contain structural units existing in 
TABLE 2. Precursors and structural characteristics of diamond-like C-phases based on the GGA and LDA calculations (LDA calculations are given in brackets)

\begin{tabular}{|c|c|c|c|c|c|c|c|c|}
\hline Phase & $\begin{array}{l}\text { Precur- } \\
\text { sor }\end{array}$ & $\begin{array}{c}\text { Ring } \\
\text { parameter }\end{array}$ & $\begin{array}{l}\text { Space } \\
\text { group }\end{array}$ & $\begin{array}{l}a, \\
\AA\end{array}$ & $\begin{array}{l}c, \\
\AA\end{array}$ & $\begin{array}{l}Z, \\
\text { at. }\end{array}$ & $\operatorname{Def},^{\circ}$ & $\begin{array}{c}S t r, \\
\AA\end{array}$ \\
\hline$c$-diam. (LA1) & \multirow[t]{2}{*}{$\begin{array}{c}\mathrm{L}_{6} \\
\text { p6mm }\end{array}$} & \multirow[t]{2}{*}{$6^{6}$} & \multirow[t]{2}{*}{$F d \overline{3} m$} & $\begin{array}{c}3.597 \\
(3.557)\end{array}$ & $\begin{array}{c}3.597 \\
(3.557)\end{array}$ & \multirow[t]{2}{*}{8} & 0.0 & 0.00 \\
\hline experiment & & & & $3.567^{a}$ & 3.567 & & - & - \\
\hline$h$-diam. (LA2) & \multirow[t]{2}{*}{$\begin{array}{c}\mathrm{L}_{6} \\
p 6 m m\end{array}$} & \multirow[t]{2}{*}{$6^{6}$} & \multirow[t]{2}{*}{$\mathrm{P}_{3} / m m c$} & $\begin{array}{c}2.528 \\
(2.499)\end{array}$ & $\begin{array}{c}4.203 \\
(4.157)\end{array}$ & \multirow[t]{2}{*}{4} & $\begin{array}{c}1.8 \\
(2.6)\end{array}$ & $\begin{array}{c}0.04 \\
(0.03)\end{array}$ \\
\hline experiment & & & & $2.52^{a}$ & 4.14 & & - & - \\
\hline $\mathrm{C}_{8}$ (LA4) & \multirow[t]{2}{*}{$\begin{array}{c}\mathrm{L}_{6} \\
p 6 m m\end{array}$} & \multirow[t]{2}{*}{$6^{6}$} & \multirow[t]{2}{*}{$I a \overline{3}$} & $\begin{array}{c}4.504 \\
(4.448) \\
\end{array}$ & $\begin{array}{c}4.504 \\
(4.448) \\
\end{array}$ & \multirow[t]{2}{*}{16} & $\begin{array}{c}44.99 \\
(46.03)\end{array}$ & $\begin{array}{c}0.34 \\
(0.313) \\
\end{array}$ \\
\hline experiment & & & & $4.279^{a}$ & 4.279 & & - & - \\
\hline CA1 & $\mathrm{C}_{4}\left(3^{3}\right)$ & $3^{3} 12^{3}$ & $F d \overline{3} m$ & $\begin{array}{c}7.588 \\
(7.516) \\
\end{array}$ & $\begin{array}{c}7.588 \\
(7.516) \\
\end{array}$ & 32 & $\begin{array}{c}254 \\
(254) \\
\end{array}$ & $\begin{array}{c}0.25 \\
(0.23) \\
\end{array}$ \\
\hline CA2 & $\begin{array}{c}\mathrm{C}_{6} \\
\left(3^{1} 4^{2}\right) \\
\end{array}$ & $3^{1} 4^{2} 8^{3}$ & $P 6_{3} / m m c$ & $\begin{array}{c}5.015 \\
(4.949) \\
\end{array}$ & $\begin{array}{c}5.062 \\
(5.031) \\
\end{array}$ & 12 & $\begin{array}{c}153 \\
(152) \\
\end{array}$ & $\begin{array}{c}0.13 \\
(0.12) \\
\end{array}$ \\
\hline CA3 & $\mathrm{C}_{8}\left(4^{3}\right)$ & $4^{3} 8^{3}$ & $\operatorname{Im} \overline{3} m$ & $\begin{array}{c}4.895 \\
(4.851)\end{array}$ & $\begin{array}{c}4.895 \\
(4.851)\end{array}$ & 16 & $\begin{array}{c}106 \\
(106)\end{array}$ & $\begin{array}{c}0.19 \\
(0.21)\end{array}$ \\
\hline CA4 & \multirow[t]{2}{*}{$\begin{array}{c}\mathrm{C}_{24} \\
\left(4^{1} 6^{2}\right)\end{array}$} & \multirow[t]{2}{*}{$4^{3} 6^{2} 8^{1}$} & \multirow[t]{2}{*}{$P m \overline{3} m$} & $\begin{array}{c}5.946 \\
(5.891)\end{array}$ & $\begin{array}{c}5.946 \\
(5.891)\end{array}$ & \multirow[t]{2}{*}{24} & $\begin{array}{c}105 \\
(105)\end{array}$ & $\begin{array}{c}0.20 \\
(0.21)\end{array}$ \\
\hline experiment & & & & $5.545^{a}$ & 5.545 & & - & - \\
\hline CA5 & $\begin{array}{c}\mathrm{C}_{16} \\
\left(4^{2} 8^{1}\right)\end{array}$ & $4^{3} 8^{3}$ & $\mathrm{I} / \mathrm{mmm}$ & $\begin{array}{c}7.185 \\
(7.124)\end{array}$ & $\begin{array}{c}4.802 \\
(4.730)\end{array}$ & 32 & $\begin{array}{c}114 \\
(114)\end{array}$ & $\begin{array}{c}0.13 \\
(0.13)\end{array}$ \\
\hline CA6 & $\begin{array}{c}\mathrm{C}_{24} \\
\left(4^{1} 6^{2}\right) \\
\end{array}$ & $4^{2} 6^{4}$ & $\operatorname{Im} \overline{3} m$ & $\begin{array}{c}4.393 \\
(4.352) \\
\end{array}$ & $\begin{array}{c}4.393 \\
(4.352) \\
\end{array}$ & 12 & $\begin{array}{c}81.1 \\
(81.1) \\
\end{array}$ & $\begin{array}{c}0.02 \\
(0.01) \\
\end{array}$ \\
\hline CA7 & $\begin{array}{c}\mathrm{C}_{48} \\
\left(4^{1} 6^{1} 8^{1}\right)\end{array}$ & $4^{3} 6^{1} 8^{2}$ & $\operatorname{Im} \overline{3} m$ & $\begin{array}{c}7.552 \\
(7.477) \\
\end{array}$ & $\begin{array}{c}7.552 \\
(7.477) \\
\end{array}$ & 48 & $\begin{array}{c}120 \\
(120)\end{array}$ & $\begin{array}{c}0.09 \\
(0.09) \\
\end{array}$ \\
\hline CA8 & $\begin{array}{c}\mathrm{C}_{48} \\
\left(4^{1} 6^{1} 8^{1}\right)\end{array}$ & $4^{3} 6^{1} 8^{2}$ & $\operatorname{Im} \overline{3} m$ & $\begin{array}{c}9.319 \\
(9.228) \\
\end{array}$ & $\begin{array}{c}9.319 \\
(9.228) \\
\end{array}$ & 96 & $\begin{array}{c}109 \\
(109)\end{array}$ & $\begin{array}{c}0.12 \\
(0.13)\end{array}$ \\
\hline CA9 & $\begin{array}{c}\mathrm{C}_{24} \\
\left(4^{1} 6^{2}\right) \\
\end{array}$ & $4^{3} 6^{2} 12^{1}$ & $F d \overline{3} m$ & $\begin{array}{c}12.44 \\
(12.32) \\
\end{array}$ & $\begin{array}{c}12.44 \\
(12.32) \\
\end{array}$ & 192 & $\begin{array}{c}114 \\
(114) \\
\end{array}$ & $\begin{array}{c}0.11 \\
(0.12) \\
\end{array}$ \\
\hline CA10 & $\begin{array}{c}\mathrm{C}_{12} \\
\left(4^{2} 6^{1}\right)\end{array}$ & $4^{3} 6^{1} 8^{2}$ & $R \overline{3} m$ & $\begin{array}{c}6.843 \\
(6.783) \\
\end{array}$ & $\begin{array}{c}7.371 \\
(7.262) \\
\end{array}$ & 36 & $\begin{array}{c}109 \\
(109) \\
\end{array}$ & $\begin{array}{c}0.18 \\
(0.18) \\
\end{array}$ \\
\hline CA11 & $\begin{array}{c}\mathrm{C}_{12} \\
\left(4^{2} 6^{1}\right)\end{array}$ & $4^{3} 6^{1} 8^{2}$ & $\mathrm{P}_{3} / m m c$ & $\begin{array}{c}6.831 \\
(6.779) \\
\end{array}$ & $\begin{array}{c}4.966 \\
(4.890) \\
\end{array}$ & 24 & $\begin{array}{c}110 \\
(110)\end{array}$ & $\begin{array}{c}0.15 \\
(0.15) \\
\end{array}$ \\
\hline CA12 & $\mathrm{C}_{4}\left(3^{3}\right)$ & $3^{3} 8^{1} 12^{2}$ & $\operatorname{Im} \overline{3} m$ & $\begin{array}{c}9.249 \\
(9.157) \\
\end{array}$ & $\begin{array}{c}9.249 \\
(9.157) \\
\end{array}$ & 48 & $\begin{array}{c}252 \\
(252)\end{array}$ & $\begin{array}{c}0.23 \\
(0.22) \\
\end{array}$ \\
\hline $\mathrm{CB}$ & $\begin{array}{c}\mathrm{C}_{48} \\
\left(4^{1} 6^{1} 8^{1}\right)\end{array}$ & $3^{1} 4^{1} 6^{2} 8^{2}$ & $F m \overline{3} m$ & $\begin{array}{c}9.513 \\
(9.420)\end{array}$ & $\begin{array}{c}9.513 \\
(9.420)\end{array}$ & 96 & $\begin{array}{c}141 \\
(141)\end{array}$ & $\begin{array}{c}0.13 \\
(0.12)\end{array}$ \\
\hline
\end{tabular}

${ }^{a}$ Ref. [2]; ${ }^{b}$ Ref. [31]; ${ }^{c}$ Ref. [32]; ${ }^{d}$ Ref. [33] 


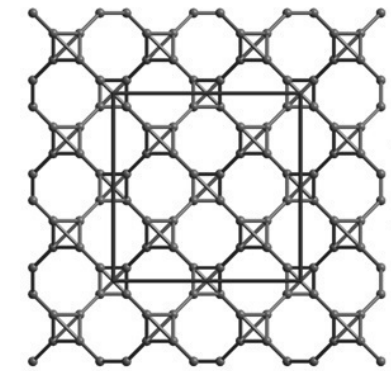

(a)

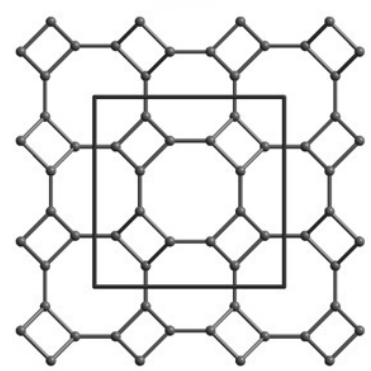

(e)

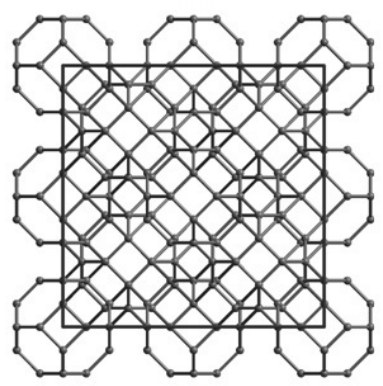

(i)

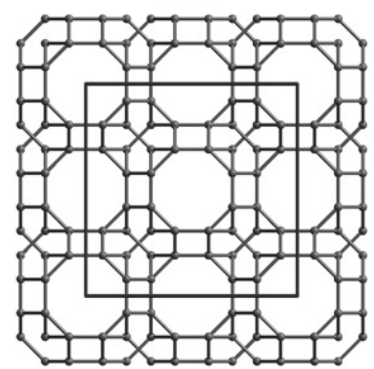

(m)

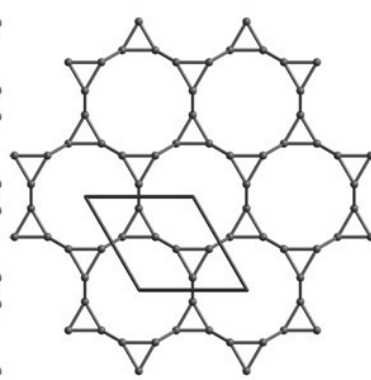

(b)

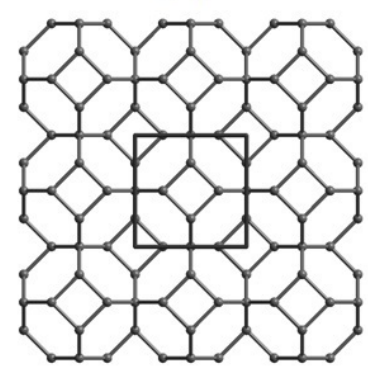

(f)

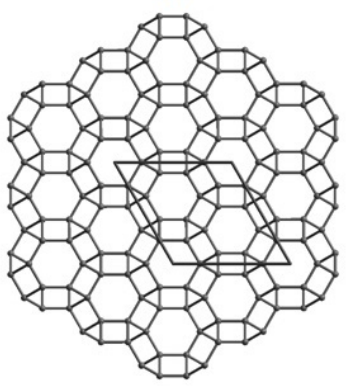

(j)

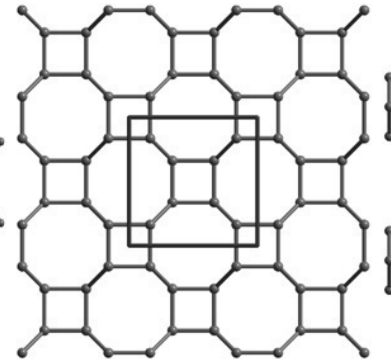

(c)

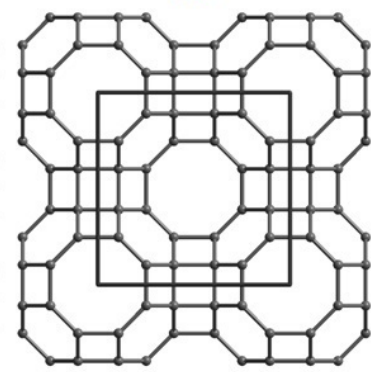

(g)

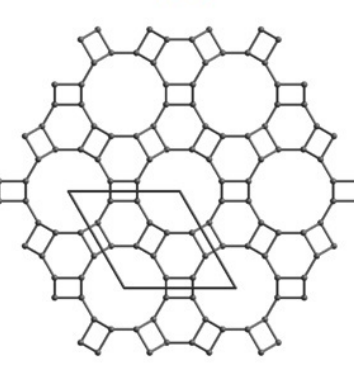

(k)

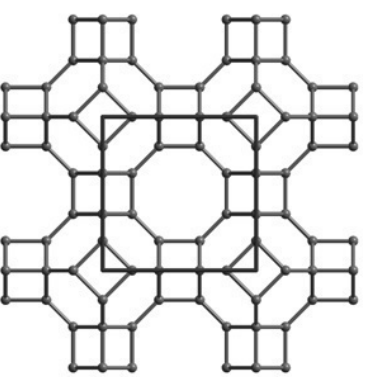

(d)

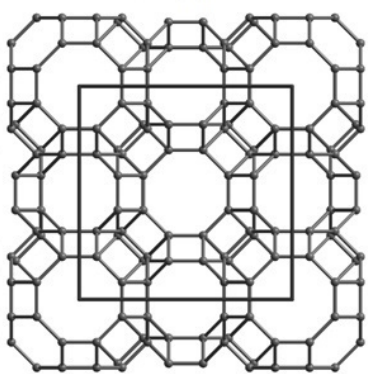

(h)

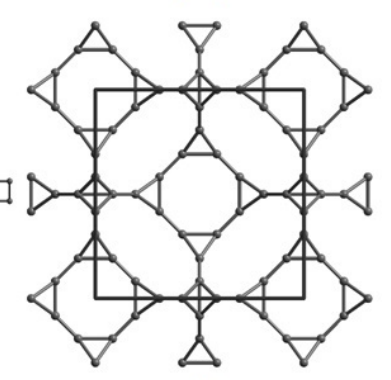

(I)

FIG. 2. The diamond-like phase structure projection onto the (001)-plane: (a) CA1; (b) CA2;

(c) CA3; (d) CA4; (e) CA5; (f) CA6; (g) CA7; (h) CA8; (i) CA9; (j) CA10; (k) CA11; (1) CA12; (m) $\mathrm{CB}$ 
TABLE 3. Density, cohesive energy $\left(\mathrm{E}_{c o h}\right)$, bandgap $\left(\mathrm{E}_{g}\right)$, bulk modulus $\left(\mathrm{B}_{0}\right)$ and hardness $(\mathrm{H})$ of diamond-like C-phases calculated by the GGA and LDA methods (LDA calculations are given in brackets)

\begin{tabular}{|c|c|c|c|c|c|}
\hline Phase & Density, $\mathrm{g} / \mathrm{cm}^{3}$ & $\mathrm{E}_{c o h}, \mathrm{eV} /$ atom & $\mathrm{E}_{g}, \mathrm{eV}$ & $\mathrm{B}_{0}, \mathrm{GPa}$ & $\mathrm{H}, \mathrm{GPa}$ \\
\hline c-diam. (exp.) & $\mathbf{3 . 5 1 7}^{a}$ & $\mathbf{7 . 3 7}^{b}$ & $\mathbf{5 . 4 8}^{b}$ & $\mathbf{4 4 3}^{b}$ & $\mathbf{9 0}^{c}$ \\
\hline LA1 & $3.428(3.546)$ & $7.86(8.96)$ & $5.44(4.61)$ & 445 & $86.6(90.8)$ \\
\hline LA2 & $3.429(3.549)$ & $7.83(8.93)$ & $5.03(3.64)$ & 445 & $86.5(90.7)$ \\
\hline LA4 & $3.492(3.627)$ & $7.11(8.22)$ & $2.70(2.12)$ & 410 & $86.0(90.5)$ \\
\hline CA1 & $1.461(1.503)$ & $6.43(7.32)$ & $2.41(1.98)$ & 177 & $36.5(38.1)$ \\
\hline CA2 & $2.171(2.242)$ & $6.92(7.87)$ & $1.90(1.55)$ & 250 & $54.4(56.9)$ \\
\hline CA3 & $2.720(2.795)$ & $7.15(8.15)$ & $3.95(3.06)$ & 346 & $67.6(70.2)$ \\
\hline CA4 & $2.276(2.342)$ & $7.06(8.04)$ & $2.91(2.30)$ & 285 & $55.9(58.2)$ \\
\hline CA5 & $2.575(2.658)$ & $6.97(7.97)$ & $2.66(1.92)$ & 316 & $63.8(66.7)$ \\
\hline CA6 & $2.824(2.904)$ & $7.44(8.46)$ & $3.96(3.18)$ & 351 & $70.9(73.8)$ \\
\hline CA7 & $2.223(2.290)$ & $6.86(7.84)$ & $3.32(2.68)$ & 270 & $54.6(56.9)$ \\
\hline CA8 & $2.366(2.436)$ & $6.96(7.95)$ & $3.11(2.50)$ & 275 & $58.3(60.7)$ \\
\hline CA9 & $1.987(2.048)$ & $6.82(7.79)$ & $3.69(3.03)$ & 239 & $48.3(50.4)$ \\
\hline CA10 & $2.402(2.482)$ & $7.02(8.00)$ & $4.37(3.56)$ & 273 & $59.3(62.0)$ \\
\hline CA11 & $2.386(2.459)$ & $6.98(7.97)$ & $4.18(3.35)$ & 280 & $58.8(61.4)$ \\
\hline CA12 & $1.210(1.247)$ & $6.35(7.24)$ & $2.14(1.72)$ & 141 & $29.6(30.9)$ \\
\hline CB & $2.224(2.290)$ & $7.16(8.14)$ & $3.34(2.70)$ & 278 & $56.3(58.6)$ \\
\hline
\end{tabular}

${ }^{a}$ Ref. [2]; ${ }^{b}$ Ref. [34]; ${ }^{c}$ Ref. [35]

synthesized saturated hydrocarbons. These phases are: (i) CA1 whose structure is based on fragments like the carbon tetrahedral skeleton of the tetrahedrane molecule [36]; (ii) CA2 containing carbon skeleton fragments similar to the carbon skeleton of experimentally obtained prismane [37]; (iii) CA3 and CA4 whose structural elements look like the cubane molecule carbon skeleton [38]; (iv) CA6 consisting of the four-membered carbon rings.

Figure 4 presents calculated electronic densities of states (DOS) of the cubic diamond and diamond-like phases derived from carbon clusters. From the DOS patterns, the bandgaps $\left(\mathrm{E}_{g}\right)$ of the phases under study were obtained (Table 3). The diamond bandgap calculated by the GGA and LDA methods differ from the experimental value [34] by 0.04 and $0.87 \mathrm{eV}$, respectively. Calculations have shown that the diamond-like phase bandgaps are narrower than that of LA1 by values varying from 20 (CA10) to $66 \%$ (CA2), i.e., C-phases are either semiconductors or insulators. Semiconductor properties may be exhibited by carbon materials based on the CA2 and CA12 phases whose structures are formed by great numbers of covalently bonded prismatic or tetrahedral clusters, respectively. Other C-phases have wider bandgaps typical for insulators. We have determined that the bandgap decreases with increasing deformation parameter Str.

To assess the mechanical characteristics of the diamond-like phases, bulk moduli (at high compression: $0.965<V / V_{0}<1$ ) and Knoop hardness (see Table 3) were calculated. Calculations of bulk modulus $\mathrm{B}_{0}$ and hardness $H$ of the cubic diamond fit well the measurements [34,35]. The bulk moduli of all the C-phases are below the LA $1 \mathrm{~B}_{0}$ by $21-68 \%$. Phases CA3, CA5, and CA6 are expected to be the least compressible among the $\mathrm{C}$-phases since their bulk moduli are comparable with that of titanium nitride [39]. A linear decrease in $\mathrm{B}_{0}$ is observed when parameter Def increases. Theoretical hardness of the C-phases is also lower than the diamond hardness by 18 to $66 \%$. The densest phases CA3 and CA6 should exhibit high strength characteristics comparable with those of boron nitride [40]. Theoretical hardness of other C-phases is higher than that of silicon carbide or almost the same [40].

XRD patterns of the diamond-like phases were calculated based on structural data obtained by the LDA method; this approximation was chosen since it provides the best fit between the calculated and measured parameters of the cubic diamond and lonsdaleite unit cells (see Table 2). The obtained C-phase XRD patterns were compared with the experimental XRD patterns of cubic diamond [41], lonsdaleite [31], cubic diamond polymorph [33], hexagonal (2H) graphite [42], and also with those of fcc $\mathrm{C}_{60}$ [43] and hexagonal close-packed (hcp) $\mathrm{C}_{70}$ [44]; 


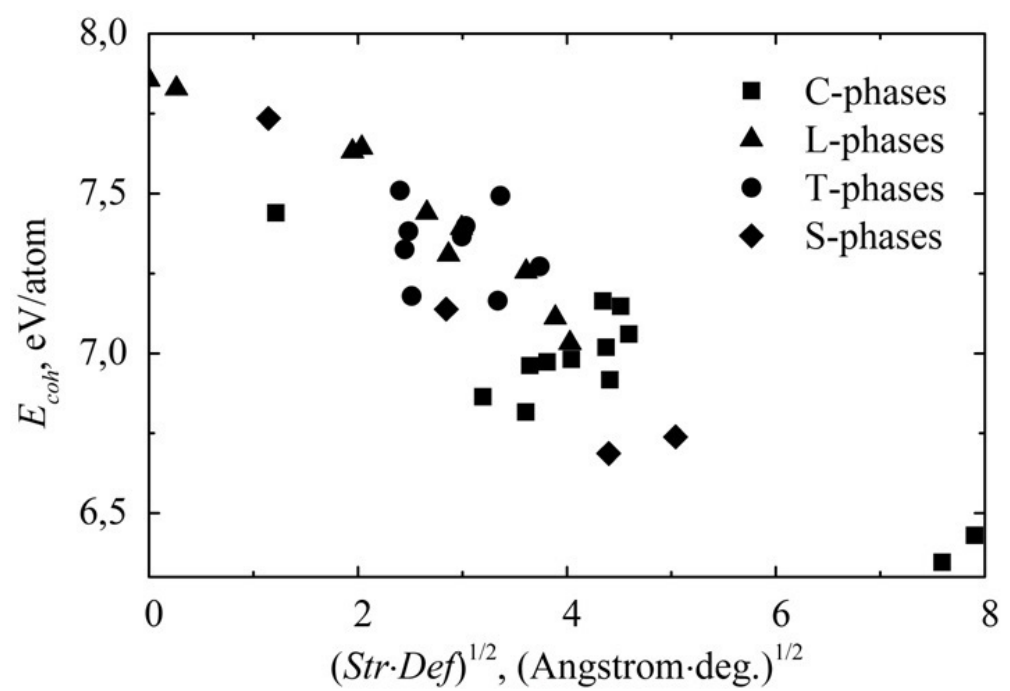

(a)

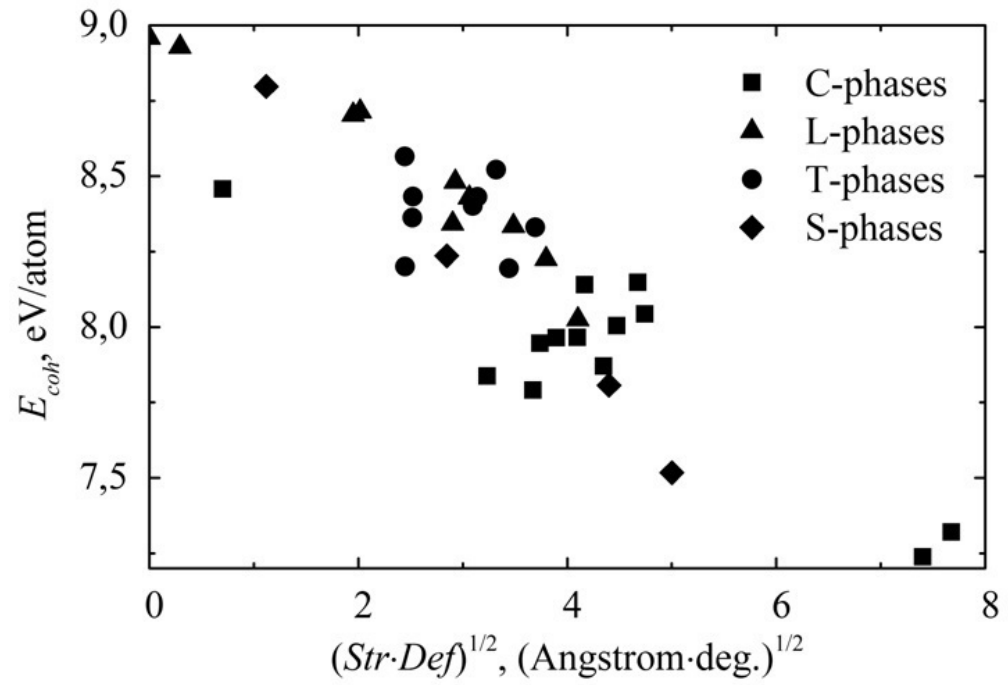

(b)

FIG. 3. Dependences of the cohesive energy $\left(\mathrm{E}_{c o h}\right)$ on the deformation parameters (Str and Def), obtained by the DFT-GGA (a) and DFT-LDA (b) methods

three main diffraction peaks are given for each in Table 4. The comparison has shown that XRD patterns of all the C-phases differ significantly from those of diamond, lonsdaleite, and cubic diamond polymorph. XRD patterns of theoretically studied diamond-like phases are comparable with those of carbon compounds consisting of 3 -coordinated atoms. For instance, positions of the CA3-phase $100 \%$ maximum and CA10-phase $9.7 \%$ maximum have been shown to be close to the main 002-maximum of graphite $(\Delta d \sim 0.05 \AA)$. The most intense maxima of phases CA1 and CA2 are located close to the $70 \%$-maximum 311 of fullerite $\mathrm{C}_{60}(\Delta d \sim 0.05 \AA)$. In the case of the CA7 diamond-like phase, the $100 \%$ maximum almost coincides with the main 110 peak of fullerite $\mathrm{C}_{70}$ $(\Delta d=0.01 \AA)$. In addition, the $79 \%$ maximum 112 of fullerite $\mathrm{C}_{70}$ may be overlapped by the $100 \%$ maxima of phases CA8 and CA10 ( $\Delta d \sim 0.07 \AA)$. The main diffraction maxima of phases CA1, CA2, CA4, CA7-CA12, and $\mathrm{CB}$ are within the diffraction angle range $(2 \theta)$ of 12.4 to $20.6^{\circ}$, which makes much easier to identify these phases. The most intense peaks of diamond-like phases CA3, CA5, and CA6 are rather close $\left(25.0-29.0^{\circ}\right)$ to the $100 \%$ maximum of hexagonal graphite; however, it may be possible to identify them by secondary diffraction peaks. 

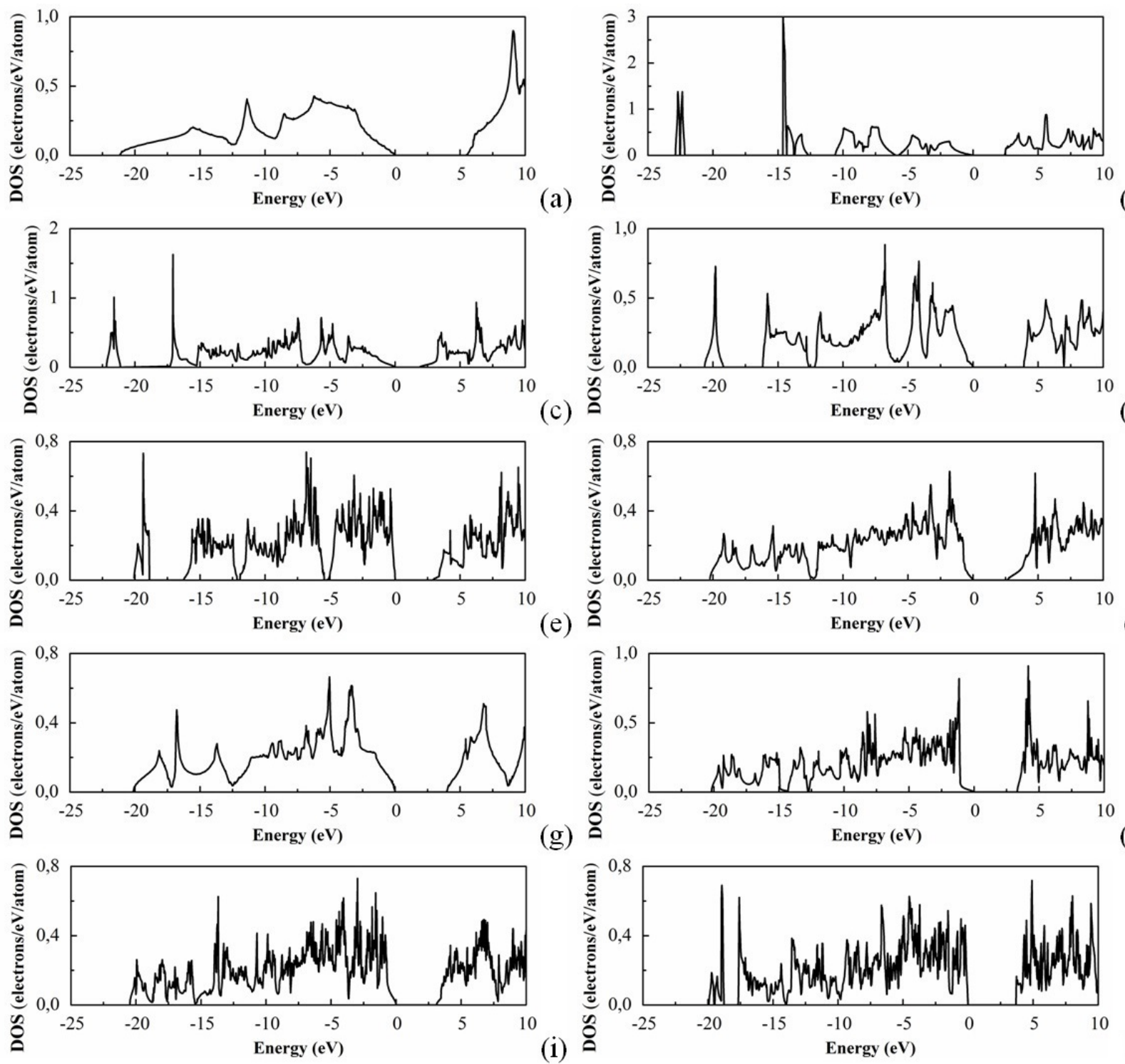

(j)
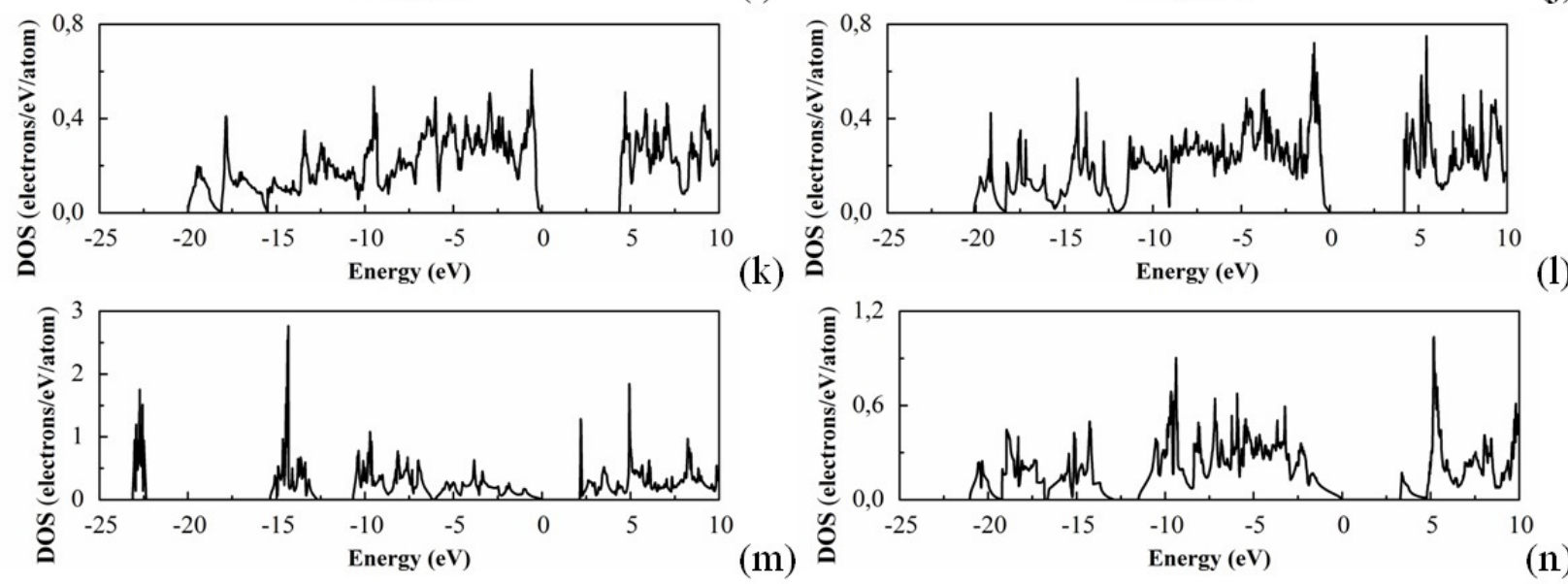

FIG. 4. Electronic density of states of diamond-like phases (the maximum energy of valence band electrons is assumed to be zero): (a) LA1; (b) CA1; (c) CA2; (d) CA3; (e) CA4; (f) CA5; (g) CA6; (h) CA7; (i) CA8; (j) CA9; (k) CA10; (1) CA11; (m) CA12; (n) CB 
TABLE 4. The most intense x-ray diffraction maxima of synthesized carbon compounds and theoretically studied diamond-like phases ( $d$ and $I$ are the interplanar distance and relative intensity of the diffraction peak, respectively)

\begin{tabular}{|c|c|c|c|c|c|c|}
\hline Phase & $d_{1}, \AA$ & $I_{1}, \%$ & $d_{2}, \AA$ & $I_{2}, \%$ & $d_{3}, \AA$ & $I_{3}, \%$ \\
\hline diamond $^{a}$ & 2.060 & 100 & 1.261 & 27 & 1.0754 & 16 \\
\hline lonsdaleite ${ }^{b}$ & 2.19 & 100 & 2.06 & 100 & 1.26 & 75 \\
\hline cubic phase $^{c}$ & 2.770 & 100 & 2.467 & 100 & 3.208 & 50 \\
\hline $2 H$ graphite $^{d}$ & 3.376 & 100 & 2.039 & 6 & 1.6811 & 4 \\
\hline$f c c \mathrm{C}_{60}{ }^{e}$ & 8.160 & 100 & 5.007 & 92 & 4.272 & 70 \\
\hline$h c p \mathrm{C}_{70}{ }^{f}$ & 5.294 & 100 & 4.510 & 79 & 8.630 & 63 \\
\hline CA1 & 4.339 & 100 & 2.657 & 8.9 & 2.170 & 3.5 \\
\hline CA2 & 4.304 & 100 & 3.270 & 33.2 & 2.152 & 8.0 \\
\hline CA3 & 3.430 & 100 & 2.426 & 33.8 & 1.534 & 23.3 \\
\hline CA4 & 5.891 & 100 & 4.165 & 28.9 & 3.401 & 14.1 \\
\hline CA5 & 3.562 & 100 & 3.941 & 63.3 & 2.643 & 31.0 \\
\hline CA6 & 3.077 & 100 & 1.777 & 19.1 & 1.256 & 12.4 \\
\hline $\mathrm{CA} 7$ & 5.287 & 100 & 3.052 & 19.4 & 3.739 & 7.6 \\
\hline CA8 & 4.614 & 100 & 6.526 & 54.5 & 2.918 & 9.7 \\
\hline CA9 & 7.113 & 100 & 4.356 & 5.1 & 3.715 & 3.5 \\
\hline CA10 & 4.548 & 100 & 3.393 & 9.7 & 2.122 & 3.6 \\
\hline CA11 & 5.871 & 100 & 3.758 & 27.4 & 3.390 & 13.9 \\
\hline CA12 & 6.475 & 100 & 3.738 & 13.9 & 4.579 & 7.5 \\
\hline $\mathrm{CB}$ & 4.710 & 100 & 5.439 & 27.9 & 2.840 & 14.4 \\
\hline
\end{tabular}

${ }^{a}$ Ref. [41]; ${ }^{b}$ Ref. [31]; ${ }^{c}$ Ref. [33]; ${ }^{d}$ Ref. [42]; ${ }^{e}$ Ref. [43]; ${ }^{f}$ Ref. [44]

\section{Conclusions}

In this paper, we have theoretically calculated structures and properties of carbon diamond-like phases derived from carbon clusters. Crystalline structures of twelve C-phases were modeled by cluster linking. The structure of one of the phases (CB) was formed by cluster superposition. Based on the DFT-GGA and DFT-LDA calculations, various structural characteristics, densities, cohesive energies, bandgaps, bulk moduli, and hardness have been determined for the C-phases. To make possible experimental identification of diamond-like phases, powder XRD patterns were simulated. We also revealed a correlation between the structural parameters and properties of the diamond-like phases derived from carbon clusters, namely: density, cohesive energy, bulk modulus and bandgap decrease with increasing deformation parameters characterizing the phase structure stress with respect to the cubic diamond.

\section{Acknowledgements}

The reported study was funded by RFBR according to the research project No. 16-33-00030 mol_a.

\section{References}

[1] Smalley R.E. Discovering the fullerenes (Nobel lecture). Angewandte Chemie International Edition in English, 1997, 36 (15), P. 15951601.

[2] Pierson H.O. Handbook of carbon, graphite, diamond, and fullerenes: properties, processing, and application. Noyes, Park Ridge, New Jersey, 1993, $402 \mathrm{p}$.

[3] Dresselhaus M.S., Dresselhaus G., Eklund P.C. Science of fullerenes and carbon nanotubes. XVIII, Academic Press, San Diego, 1996, 965 p.

[4] Sheka E. Fullerenes: nanochemistry, nanomagnetism, nanomedicine, nanophotonics. CRC Press, Taylor \& Francis Group, Boca Raton, 2011, 312 p.

[5] Osawa E. Perspectives of fullerene nanotechnology. Kluwer Academic Pub., Dordrecht-Boston-London, $2002,386 \mathrm{p}$.

[6] Nunez-Regueiro M., Monceau P., Rassat A., Bernier P., Zahab A. Absence of a metallic phase at high pressure in C 60. Nature, 1991, 354, P. 289-291. 
[7] Duclos S.J., Brister K., Haddon R.C., Kortan A.R., Thiel F.A. Effects of pressure and stress on C 60 fullerite to 20 GPa. Nature, 1991 , 351, P. 380-382.

[8] Yoo C.S., Nellis W.J. Phase transformations in carbon fullerenes at high shock pressures. Science, 1991, 254, P. 1489-1491.

[9] Moshary F., Chen N.H., Silvera I.F, Brown C.A., Dorn H.C., de Vries M.S., Bethune D.S. Gap reduction and the collapse of solid C60 to a new phase of carbon under pressure. Physical Review Letters, 1992, 69, P. 466-469.

[10] Bashkin I.O., Rashchupkin V.I., Gurov A.F., Moravsky A.P., Rybchenkot O.G., Kobelev N.P. A new phase transition in the T-P diagram of $\mathrm{C}_{60}$ fullerite. Journal of Physics: Condensed Matter, 1994, 6, P. 7491-7498.

[11] Nunez-Regueiro M., Monceau P., Hodeau J.-L. Crushing $\mathrm{C}_{60}$ to diamond at room temperature. Nature, 1992, 355, P. $237-239$.

[12] Hodeau J.-L., Tonnerre J.M., Bouchet-Fabre B., Nunez-Regueiro M., Capponi J.J., Perroux M. High-pressure transformations of C 60 to diamond and $\mathrm{sp}^{3}$ phases at room temperature and to $\mathrm{sp}^{2}$ phases at high temperature. Physical Review B, 1994, 50, P. 10311-10314.

[13] Hirai H., Kondo K.-I., Ohwada T. Quenching a transition of C60 fullerene to diamond under shock compression. Carbon, 1993, 31(7), P. $1095-1098$.

[14] Burdett J.K., Lee S. The moments method and elemental structures. Journal of the American Chemical Society, 1985, 107, P. 3063-3082.

[15] Pokropivny V.V., Pokropivny A.V. Structure of "cubic graphite": simple cubic fullerite C 24 . Physics of the Solid State, 2004, 46(2), P. 392-394.

[16] Chen X.-Q., Niu H., Franchini C., Li D., Li Y. Hardness of T-carbon: density functional theory calculations. Physical Review B, 2011, 84, P. $121405(\mathrm{R})$.

[17] Pokropivny A., Volz S. "C8 phase": supercubane, tetrahedral, BC-8 or carbon sodalite? Physica Status Solidi B, 2012, 249(9), P. 17041708.

[18] Hu M., Tian F., Zhao Z., Huang Q., Xu Bo, Wang Li-M., Wang H.-T., Tian Y., He J. Exotic cubic carbon allotropes. The Journal of Physical Chemistry C, 2012, 116, P. 24233-24238.

[19] Belenkov E.A., Greshnyakov V.A. Classification schemes of carbon phases and nanostructures. New Carbon Materials, 2013, 28(4), P. 273-283.

[20] Belenkov E.A., Brzhezinskaya M.M., Greshnyakov V.A. Novel carbon diamond-like phases LA5, LA7 and LA8. Diamond and Related Materials, 2014, 50, P. 9-14.

[21] Belenkov E.A., Greshnyakov V.A. Structures and properties of diamond-like phases derived from carbon nanotubes and three-dimensional graphites. Journal of Materials Science, 2015, 50(23), P. 7627-7635.

[22] Belenkov E.A., Greshnyakov V.A. New structural modifications of diamond: LA9, LA10, and CA12. Journal of Experimental and Theoretical Physics, 2014, 119(1), P. 101-106.

[23] Hohenberg P., Kohn W. Inhomogeneous electron gas. Physical Review, 1964, 136(3B), P. 864-871.

[24] Giannozzi P., Baroni S., Bonini N., Calandra M., Car R., Cavazzoni C., Ceresoli D., Chiarotti G.L., Cococcioni M., Dabo I., Corso A.D., de Gironcoli S., Fabris S., Fratesi G., Gebauer R., Gerstmann U., Gougoussis C., Kokalj A., Lazzeri M., Martin-Samos L., et al. QUANTUM ESPRESSO: a modular and open-source software project for quantum simulations of materials. Journal of Physics: Condensed Matter, 2009, 21(39), P. 395502.

[25] Becke A.D., Density-functional thermochemistry. III. The role of exact exchange. The Journal of Chemical Physics, 1993, 98, P. 56485652.

[26] Perdew J.P., Zunger A. Self-interaction correction to density-functional approximations for many-electron systems. Physical Review B, 1981, 23(10), P. 5048-5079.

[27] Monkhorst H.J., Pack J.D. Special points for Brillonin-zone integrations. Physical Review B, 1976, 13(12), P. 5188-5192.

[28] Greshnyakov V.A, Belenkov E.A. Technique for calculating the bulk modulus. Russian Physics Journal, $2014,57(6)$, P. $731-737$.

[29] Li K., Wang X., Zhang F., Xue D. Electronegativity identification of novel superhard materials. Physical Review Letters, 2008, 100, P. 235504.

[30] Guinier A. Theorie et technique de la radiocristallographie. 3-rd ed., A. Dunod, Paris, 1964, 740 p.

[31] Bundy F.P., Kasper J.S. Hexagonal diamond - a new form of carbon. The Journal of Chemical Physics, 1967, 46(9), P. 3437-3446.

[32] Matyushenko N.N., Strel'nitskii V.E., Gusev V.A. A dense new version of crystalline carbon C 8 . Journal of Experimental and Theoretical Physics Letters, 1979, 30(4), P. 199-202.

[33] Aust R.B., Drickamer H.G. Carbon: a new crystalline phase. Science, 1963, 140(3568), P. 817-819.

[34] Kittel C. Introduction to solid states physics. 7-th ed., Wiley, New York, 1996, 673 p.

[35] Brookes C.A., Brookes E.J. Diamond in perspective: a review of mechanical properties of natural diamond. Diamond and Related Materials, 1991, 1, P. 13-17.

[36] Maier G., Pfriem S., Schafer U., Matusch R. Tetra-tert-butyltetrahedrane. Angewandte Chemie International Edition in English, 1978, 17(7), P. 520-521.

[37] Katz T.J., Acton N. Synthesis of prismane. Journal of the American Chemical Society, 1973, 95(8), P. $2738-2739$.

[38] Eaton P.E., Cole T.W. Jr. The cubane system. Journal of the American Chemical Society, 1964, 86, P. $962-964$.

[39] Chen H., Peng F., Mao Ho-K., Shen G., Liermann H.-P., Li Z., Shu J. Strength and elastic moduli of TiN from radial x-ray diffraction under nonhydrostatic compression up to $45 \mathrm{GPa}$. Journal of Applied Physics, 2010, 107, P. 113503.

[40] Chen X.-Q., Niu H., Li D., Li Y. Modeling hardness of polycrystalline materials and bulk metallic glasses. Intermetallics, 2011, 19, P. $1275-1281$.

[41] Powder Diffraction File Number 6-675. Inorganic Crystal Structure Database. FIZ Karlsruhe, Leibniz-Institut für Informationsinfrastruktur $\mathrm{GmbH}$.

[42] Powder Diffraction File Number 41-1487. Inorganic Crystal Structure Database. FIZ Karlsruhe, Leibniz-Institut für Informationsinfrastruktur GmbH.

[43] Powder Diffraction File Number 44-558. Inorganic Crystal Structure Database. FIZ Karlsruhe, Leibniz-Institut für Informationsinfrastruktur $\mathrm{GmbH}$.

[44] Powder Diffraction File Number 48-1206. Inorganic Crystal Structure Database. FIZ Karlsruhe, Leibniz-Institut für Informationsinfrastruktur GmbH. 